\title{
Reproduction and marriage among male survivors of cancer in childhood, adolescence and young adulthood: a national cohort study
}

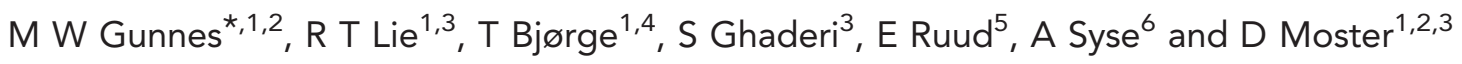 \\ ${ }^{1}$ Department of Global Public Health and Primary Care, University of Bergen, Postboks 7804, Bergen 5018, Norway; ${ }^{2}$ Department \\ of Pediatrics, Haukeland University Hospital, Bergen 5021, Norway; ${ }^{3}$ Norwegian Institute of Public Health, Bergen 5018, Norway; \\ ${ }^{4}$ Cancer Registry of Norway, Oslo 0304, Norway; ${ }^{5}$ Department of Pediatric Medicine, Oslo University Hospital, Oslo 0424, Norway \\ and ${ }^{6}$ Department of Research, Statistics Norway, Oslo 0033, Norway
}

Background: Increased survival after cancer in young age has made long-term follow-up studies of high external validity important. In this national cohort study, we explored the impact of cancer in young age on reproduction and marital status in male survivors.

Methods: Hazard ratios (HRs) and relative risks (RRs) of reproductive and marital outcomes were studied for male survivors of cancer in young age ( $<25$ years) and cancer-free male comparisons, born during 1965-1985, by linking compulsory national registries in Norway.

Results: Male cancer survivors $(n=2687)$ had reduced paternity (HR: 0.72, 95\% confidence interval (Cl): 0.68-0.76). This was most apparent in survivors of testicular cancer, brain tumours, lymphoma, leukemia and bone tumours, and when diagnosed with cancer before 15 years of age. Male cancer survivors were more likely to avail of assisted reproduction (RR: 3.32, 95\% CI: 2.68-4.11). There was no increased risk of perinatal death, congenital malformations, being small for gestational age, of low birth weight or preterm birth in their first offspring. Male cancer survivors were less likely to marry (HR: 0.93, 95\% Cl: 0.86-1.00), in particular brain tumour survivors.

Conclusions: In this national cohort study, we demonstrated reduced paternity and increased use of assisted reproduction among male cancer survivors, but no adverse outcome for their first offspring at birth.

The number of survivors after treatment of cancer in childhood, adolescence and young adulthood has steadily increased over the past decades (Steliarova-Foucher et al, 2004), due to improvements in treatment regimens and supportive care. It is now expected that close to $80 \%$ of those diagnosed with cancer during childhood or adolescence will survive their cancer and subsequent treatment (Steliarova-Foucher et al, 2004; Gatta et al, 2014). This leads to a growing number of adults in need of specialised care and counselling during specific life events, such as attempts to establish a family and reproductive health issues. In the United States, $\sim 1$ out of 530 adults between the age of 20 and 39 years is currently a survivor of paediatric cancer (Ward et al, 2014) and this number is expected to rise as the survivors of the recent decades with improved cancer treatment reach adult age.

However, as treatment for these cancers has become more successful, the concern regarding severe late effects has also increased. Adult survivors of childhood cancer have a high prevalence of adverse health outcomes, especially pulmonary, cardiac and endocrine (Hudson et al, 2013; de Fine Licht et al, 2014; Gudmundsdottir et al, 2015), as well as risk of secondary malignancies (Oeffinger et al, 2006; Geenen et al, 2007; Olsen et al, 2009).

*Correspondence: Dr MW Gunnes; E-mail: maria.gunnes@uib.no

Received 27 August 2015; revised 24 November 2015; accepted 4 December 2015; published online 21 January 2016

(c) 2016 Cancer Research UK. All rights reserved 0007-0920/16 
The effects of previous cancer treatment on pregnancy and reproductive outcomes among female survivors diagnosed with cancer in young age are relatively well explored (Green et al, 2009; Reulen et al, 2009; Signorello et al, 2012). Less detailed and comprehensive information is, however, available regarding male survivors and studies are often hampered by a limited number of participants, selection bias and low power (Green et al, 2010; Tromp et al, 2011; Van Dorp et al, 2012; Wasilewski-Masker et al, 2014). The objective of this study was to examine detailed reproductive outcomes of men diagnosed with cancer before the age of 25 years in a complete, national cohort. By linking several compulsory national databases in Norway holding medical, social and demographic data, we assessed medical aspects of reproduction at a population level (paternity, the use of assisted reproductive technology (ART) and offspring outcomes) and also whether a potential difference in paternity rates could be explained by a difference in the ability to find a partner (social aspect of reproduction). Our registry design rewarded us a large populationbased cohort of high scientific validity available for analysis.

\section{MATERIALS AND METHODS}

Data sources. The Cancer Registry of Norway (CRN) has received information on all patients with a cancer diagnosis since 1953. Reporting is mandatory for all clinicians and pathologists in Norway (Cancer Registry of Norway, 2013), and information about site, histological type and stage of disease at the time of diagnosis is recorded. The completeness of the $\mathrm{CRN}$ has been found to be $>95 \%$ (Larsen et al, 2009), consistent with other Northern European cancer registries (Gatta et al, 2014). Cancer Registry of Norway provided information on the cancer cases including date of diagnosis, site (International Classification of Disease, Seventh Edition (ICD-7; World Health Organization, 1957) and, for some diagnoses (leukemia, lymphoma and central nervous system (CNS) tumours), tumour morphology (Manual of Tumor Nomenclature and Coding (MOTNAC; American Cancer Society, 1968) for cancers diagnosed until 1992 and International Classification of Diseases for Oncology, Second Edition (ICD-O-2) morphology codes from 1993 onwards (World Health Organization, 1990; Larsen et al, 2009)).

The Medical Birth Registry of Norway (MBRN) holds information on all births in Norway since 1967 (Irgens, 2000; Medical Birth Registry of Norway, 2013). The Medical Birth Registry of Norway is based on compulsory notification of every birth or late abortion from 16 weeks of gestation onwards and includes identification of the parents, complications during pregnancy and delivery, length of pregnancy, as well as information on the infant. The registry contains information on the use of ART from 1984 and close to complete data on the uptake of ART services in Norway, including method of treatment (in-vitro fertilisation, intracytoplasmic sperm injection (ICSI), combination or nonspecified), is available from 1988 onwards (Romundstad et al, 2008). We identified members of the study cohort registered in MBRN as fathers. For their first offspring, MBRN provided information on stillbirths and neonatal deaths, gestational age, birth weight, congenital anomalies and whether the birth was a result of ART (including method).

The Central Population Registry contains demographic information on all residents in Norway from 1960 onwards (Norwegian Tax Administration, 2015). The registry provided date of birth, emigration or death and information on marital status. Data on education were provided by the Norwegian National Education Database, where all education statistics on an individual level has been registered since 1970 (National Education Database, 2013).
Every resident in Norway has since 1960 been assigned a unique 11-digit personal identification number, which enables precise record linkage between registries.

Study cohort. Our study cohort consisted of all males born alive in Norway during the 20-year period from 1965 through 1985. Those who lacked an identification number, emigrated or died before the start of reproductive age (defined here as 15 years) were excluded $(n=16140)$. The cancer cases were identified through the CRN and information was available for cancers diagnosed through 31 December 2007. We excluded those who had an uncertain basis for their cancer diagnosis or a cancer diagnosis at autopsy only $(n=217)$. The cancer site grouping used for this study was based on a modified version of the International Classification of Childhood Cancer, Second Edition (Kramarova and Stiller, 1996), based on ICD-O-2 and MOTNAC morphology codes, as well as ICD-7 topography codes. For the tumours of the CNS, we divided the cancer diagnoses into low- and high-grade tumours according to the WHO classification (Louis et al, 2007). The term cancer survivor was used to encompass all individuals diagnosed with cancer before age 25 years and surviving beyond reproductive age (15 years of age).

The male cancer survivors who were diagnosed with a second cancer $(n=82)$ during follow-up were excluded from the analyses. There were missing data on marital status for 4539 individuals including 143 of the cancer survivors.

Statistical analyses. We estimated the hazard ratio (HR) with a 95\% confidence interval (CI) of fathering a first offspring in the male cancer survivors compared with the non-cancer male group, using Cox regression. We started follow-up at 15 years of age, ended at the date of birth of the first offspring and censored at death, emigration or 31 December 2011, whichever occurred first. We then categorised the cancer cohort into diagnostic groups (as described), age at diagnosis (0-14 years, $15-19$ years and 20-24 years) and diagnostic time periods (1965-79, 1980-94 and 1995-2007), and repeated the analyses on these subgroups. In order to fully make use of the prospective nature of our data and account for changes in the hazard rates over time, we formed a time-dependent Cox regression model. For this model studying paternity (defined as the date of birth of the first offspring) as outcome, we defined age at cancer diagnosis as a time-dependent covariate. This covariate was equal to 0 as long as the cohort member had not been diagnosed with cancer before the age of 25 years and changed value to 1 when cancer $(<25$ years of age $)$ was diagnosed. For the cohort member diagnosed with cancer before 15 years of age, this covariate was equal to 1 at the start of the follow-up. By using this model, the cancer survivors fathering their first child before their cancer was diagnosed $(n=72)$ were included in the non-cancer comparison group for this analysis. We decided to study the first offspring only, as this is the most unambiguous measure of parenthood in the absence of both treatment data and data on reproductive desire.

Adjustments were made by including year of birth of the cohort members as a continuous variable, as well as parental education (highest educational level achieved by the parents of the cohort) as a categorical variable, divided into three categories: lower education $(<11$ years), intermediate (11-14 years) and tertiary education ( $>14$ years).

For the analysis on marriage, this was similarly modelled as described above, with an extended Cox model including age at cancer diagnosis as a time-dependent covariate. The follow-up ended at the date of first marriage and cases were censored at death, emigration or 31 December 2007, whichever occurred first. Thus, the male cancer survivors who married before receiving their cancer diagnosis were included in the non-cancer reference group 
for the analysis on marriage. This was done to make correct use of the prospective nature of the data and to avoid conditioning on a future cancer diagnosis. We then analysed paternity in the married men only, for the cancer survivors compared with the cancer-free male reference group. In this analysis, we started follow-up of the childless males at the age of 15 years and ended at the date of birth of the cohort member's first offspring, censoring at death, emigration or 31 December 2011, whichever occurred first. Here, a standard Cox proportional hazard regression model was employed and only the married men $(n=204652)$ were part of this sub-analysis. In addition to adjustments described for the previous analyses, this analysis was also adjusted for the cohort member's age at marriage.

We estimated the relative risk (RR) of perinatal death (comprising stillbirth $>22$ weeks gestation and neonatal death $<28$ days), congenital anomalies, preterm birth (subdivided into gestational age of 22-28 weeks and 29-36 weeks), low birth weight (subdivided into birth weight of 500-1499 g and 1500-2499 g), small for gestational age (SGA) and the risk of the pregnancy being conceived using assisted reproduction, in the male cancer survivors first offspring compared with the first offspring of the cancer-free reference group. A log binomial regression model was employed and the results are presented as RRs with 95\% CIs. For the analysis on prematurity, low birth weight and SGA, we included only singleton pregnancies. Small for gestational age was defined as birthweight below -2 s.d. from the mean, sex-specific for each gestational age in weeks (Skjærven et al, 2000). Adjustments were made for birth year of the offspring's father (the cohort member) and age of the offspring's mother (the partner of the cohort member).
SPSS version 21 (IBM SPSS, Armonk, NY, USA) and STATA version 12 (StataCorp LP, College Station, TX, USA) were used for statistical analyses. Figure 1 was made in $\mathrm{R}$ statistical software version 3.2.2 ( $\mathrm{R}$ Foundation for Statistical Computing, Vienna, Austria). The study was approved by the Norwegian Data Protection Authority and the Regional Committee for Medical and Health Research Ethics for Western Norway.

\section{RESULTS}

A total of 626495 males were born in Norway from 1965 through 1985. After excluding those who emigrated or died before fertile age, the study cohort comprised 2687 cancer survivors diagnosed with cancer before the age of 25 years and 607668 cancer-free male comparisons (Table 1). There were 1087 first offspring among the male cancer survivors, the corresponding number being 368469 in the male noncancer reference group. Thirty per cent of the cancer cases were diagnosed in childhood (0-14 years of age), $26 \%$ in adolescence (15-19 years) and $43 \%$ in young adulthood ( $20-24$ years). There were relatively few survivors being diagnosed in the first time period of 1965-1979 (9\%) and thus the majority was diagnosed after 1980 (Table 1).

The most prevalent cancer type overall was gonadal and germ cell tumours $(27 \%$ of which the majority were diagnosed as young adults), hereafter referred to as 'testicular cancer', followed by CNS tumours (18\%), lymphoma (15\%) and leukemia (13\%; Table 1).

We observed a significant reduction in paternity in the male cancer survivors (HR: 0.72, 95\% CI: 0.68-0.76) compared with the non-cancer males (Figure 1A). Divided into cancer site, we found
A

Paternity in men diagnosed with cancer before 25 years of age

Cancer site

I. Leukemia -Acute lymphoblastic

-Acute myeloid

-Unspecified

II. Lymphoma

-Hodgkin

-Non-Hodgkin

-Unspecified

III. Central nervous system tumours

-Low grade

- High grade

-Unspecified

IV Sympathetic nervous system tumours

V. Retinoblastoma

VI. Renal tumours

VIII. Malignant bone tumours

IX. Soft-tissue sarcomas

$X$ Germ cell/gonadal neoplasms

XI. Carcinomas and other epithelial neoplasm

- Thyroid carcinoma

-Malignant melanoma

All cancers

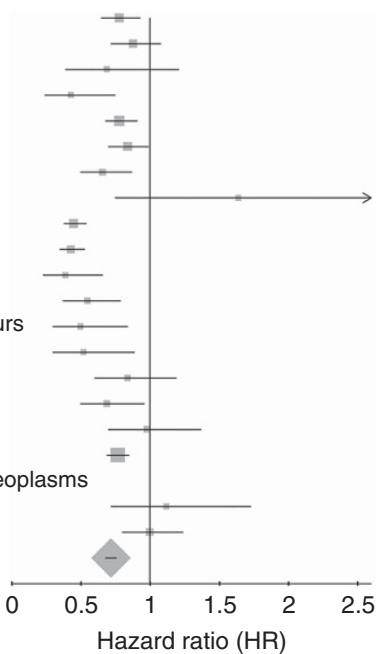
HR

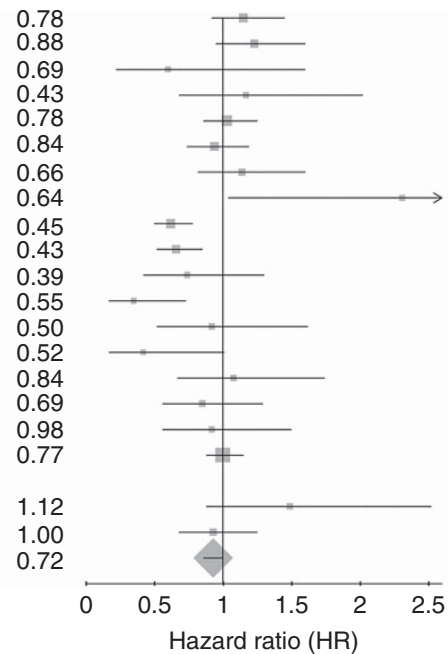
Paternity in married men diagnosed with cancer before 25 years of age HR

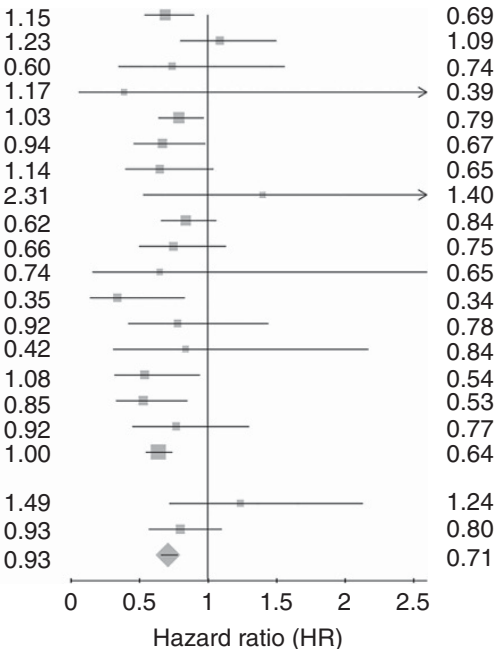

Figure 1. Forest plot of hazard ratios for paternity and marriage. (A) Hazard ratios (HRs) with $95 \% \mathrm{Cls}$ of fathering a first offspring after cancer diagnosis, for all cancer survivors ( $n=2605$, secondary malignancies excluded), subdivided into different cancer diagnoses, with the non-cancer male population as reference $(n=607668)$. (B) Hazard ratios with $95 \% \mathrm{Cls}$ of marriage in the cancer survivors $(n=2462)$, with the cancer-free male population as reference $(n=603272$ ). (C) Hazard ratios with $95 \% \mathrm{Cls}$ of fathering a first offspring in the married population only, in the cancer survivors ( $n=667)$ versus the male non-cancer reference population $(n=203985)$. The horizontal lines through the squares represent $95 \% \mathrm{Cl}$, arrows indicate upper $\mathrm{Cl}$ above 2.5. Solid boxes indicate HR in each cancer group with dimensions proportional to weights (inverse of s.d.). The diamonds represent the pooled HR for all cancers, with $95 \% \mathrm{Cl}$. All analyses are adjusted for birth year of the cohort members (father) and education of parents; and for the analysis presented in $\mathbf{C}$, adjustment was also made for age (of cohort member) at marriage. Age at cancer diagnosis was entered as a time-varying covariate in the extended Cox regression analysis for $\mathbf{A}$ and $\mathbf{B}$. Only results from cancer groups containing $>30$ survivors are depicted. The cancer site grouping used is a modified version of the International Classification of Childhood Cancer (Kramarova and Stiller, 1996), based on ICD-O-2 and MOTNAC morphology codes and ICD-7 topography codes. The grading of CNS tumours is based on the 2007 WHO classification of tumours of the CNS (Louis et al, 2007). 
Table 2. RR with $95 \% \mathrm{Cl}$ for selected first offspring outcomes

\begin{tabular}{|c|c|c|c|c|}
\hline Offspring outcome & $\begin{array}{l}\text { Male cancer survivors }{ }^{a} \\
\text { (\% of total first offspring) }\end{array}$ & $\begin{array}{c}\text { Non-cancer male reference population } \\
\text { ( } \% \text { of total first offspring) }\end{array}$ & $\mathrm{RR}^{\mathrm{b}}$ & $95 \% \mathrm{Cl}$ \\
\hline Perinatal death ${ }^{c}$ & $6(0.6)$ & $2424(0.7)$ & 0.72 & $0.33-1.61$ \\
\hline Congenital malformation $^{d}$ & $42(3.9)$ & $15395(4.2)$ & 0.92 & $0.69-1.24$ \\
\hline Premature delivery ${ }^{\mathbf{e}}$ & $52(4.9)$ & $21490(5.9)$ & 0.83 & $0.63-1.08$ \\
\hline 22-28 Weeks & $1(0.1)$ & $1625(0.4)$ & 0.21 & $0.03-1.50$ \\
\hline 29-36 Weeks & $51(4.8)$ & $19955(5.5)$ & 0.87 & $0.67-1.14$ \\
\hline Low birth weight ${ }^{\mathbf{e}}$ & $30(3.0)$ & $15865(4.4)$ & 0.69 & $0.49-0.97$ \\
\hline $500-1499 \mathrm{~g}$ & $5(0.5)$ & $2927(0.8)$ & 0.59 & $0.25-1.41$ \\
\hline $1500-2499 \mathrm{~g}$ & $25(2.4)$ & $12165(3.4)$ & 0.70 & $0.48-1.04$ \\
\hline$S G A^{e, f}$ & $17(1.6)$ & $7.979(2.2)$ & 0.75 & $0.46-1.19$ \\
\hline \multicolumn{5}{|c|}{ 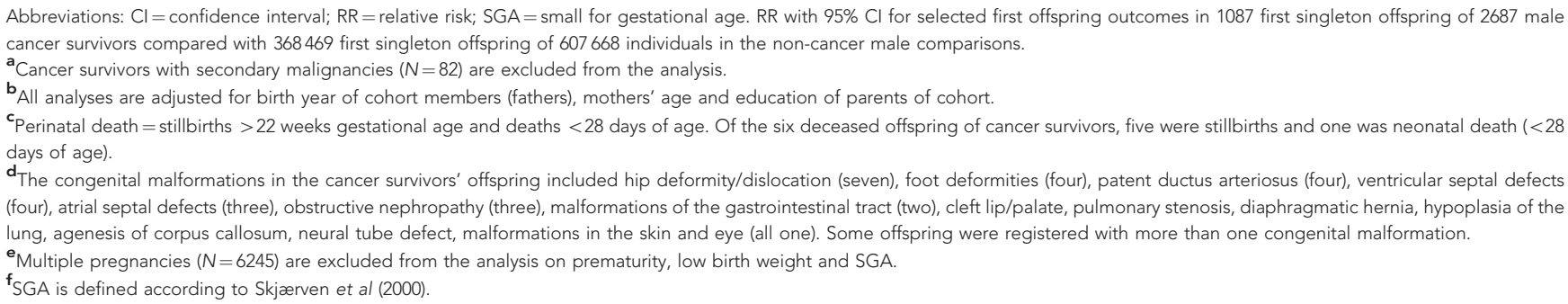 } \\
\hline
\end{tabular}

there was a significantly increased usage of ICSI compared with in vitro fertilisation and unspecified methods in the partners of male cancer survivors compared with the partners of the male non-cancer reference group (RR: 1.51, 95\% CI: 1.25-1.81; Supplementary Table). Male cancer survivors had a slightly lower likelihood of getting married compared with the non-cancer group (HR: 0.93, 95\% CI: 0.86-1.00; Figure 1B). In the CNS tumour group, there was a significantly decreased likelihood of marriage in the low-grade and nonspecific tumour groups, but in the highgrade group this reduction was not significant. For survivors of testicular cancer, lymphoma and leukemia, we found similar marriage rates to the non-cancer male group (Figure 1B). When analysing the married sub-cohort only, the paternity deficit for the male cancer survivors remained (HR: 0.71, 95\% CI: 0.66-0.78; Figure 1C), and especially in the subgroups of testicular cancer, lymphoma and leukemia. The reduced paternity in the CNS tumour group, however, was less pronounced when restricting analyses to the married individuals only.

\section{DISCUSSION}

In this national cohort study of Norwegian males born over a 20year period, we found significantly reduced paternity in men diagnosed with cancer before the age of 25 years when compared with the non-cancer reference group, especially when diagnosed with cancer before age 15 years. Pregnancies conceived by ART were significantly increased, but we could not demonstrate any increased risk for adverse outcomes among the first offspring of the survivors. Male cancer survivors had a slightly lower probability to marry and the paternity deficit persisted when analysing the married individuals only, except for the CNS tumour group.

One strength of the study is the use of compulsory national registries not prone to selection bias and with minimal loss to follow-up. Thus, our sample size is large and fully complete on a population level. Furthermore, health care in Norway is free of charge and provided independent of geographical location and patient age (Molven and Ferkis, 2011).

A weakness of the study is the lack of detailed information on individual cancer treatment. However, treatment for childhood cancer in Norway has for the past 30 years been standardised by common Nordic or European treatment protocols, and given at a small number of centres, ensuring identical treatment regimens for all children with cancer (Gustafsson et al, 2000; Pritchard-Jones et al, 2013) and making assumptions as to which treatments have been given in this group possible (Gustafsson et al, 1998; Moe et al, 1997).

The great majority of male cancer survivors in our study were diagnosed after 1980 (>90\%, Table 1) and for some cancer sites there have been major changes in treatment regimens with regards to gonadotoxicity since then. For testicular cancer, with the introduction of retroperitoneal lymph node dissection and cisplatin-based chemotherapy from 1980 onwards, this is regarded as a major paradigm shift in the treatment (Fosså and Kravdal, 2000). For CNS tumours, there has been no major change in treatment given over the past decades (Stensheim et al, 2011). For $\mathrm{HL}$ in paediatric and adolescent patients, there has been an ongoing process of reducing (and in selected cases omitting) radiation since 1995 (Dörffel et al, 2013) as well as a shift towards less gonadotoxic chemotherapy regimens $(\mathrm{GPOH}, 2015)$. For (young) adult HL patients this has been a slower but nonetheless ongoing process (Kiserud et al, 2007). In the case of non-HL, there are no major changes in treatment strategies since 1980 (Stensheim et al, 2011). For paediatric leukemia, omitting cranial irradiation and replacing it with intermediate- and high-dose methotrexate intravenously and intrathecally, has been the standard therapy in Norway since 1975 (Moe et al, 1981). The agents in use for the treatment of paediatric leukemia have not been subject to major changes over the past few decades, although treatment combinations and dosages have changed. There has been a significant reduction in the use of irradiation for most paediatric cancers over the past four decades (Jairam et al, 2013).

Our information regarding ART does not take into account those who have attempted ART not leading to a successful pregnancy. Our ART rates therefore serve as a surrogate marker for ART attempts. There is no evidence to support that cancer survivors would have a higher success rate from ART than cancerfree individuals, thereby leading to an overestimation of the uptake (García et al, 2014). There is no information in the MBRN on the use of sperm donors, which would have been useful for our study. ART has been associated with adverse pregnancy outcomes (Romundstad et al, 2008); however, despite an increased use of 
Table 3. RR with $95 \% \mathrm{Cl}$ for pregnancies resulting from ART

\begin{tabular}{|c|c|c|c|}
\hline Diagnostic groups ${ }^{a}$ & $\begin{array}{l}\text { Offspring from ART } \\
\text { (total offspring) }\end{array}$ & $\mathrm{RR}^{\mathrm{b}}$ & $95 \% \mathrm{Cl}$ \\
\hline No cancer & $8278(368469)$ & 1.00 & (Ref) \\
\hline All cancer ${ }^{c}$ & $80(1087)$ & 3.32 & $2.69-4.10$ \\
\hline $\begin{array}{l}\text { I. Leukemia } \\
\text { Lymphoblastic leukemia } \\
\text { Myeloid leukemia } \\
\text { Leukemia, unspecified }\end{array}$ & $\begin{array}{l}6(121) \\
3(95) \\
1(12) \\
2(14)\end{array}$ & $\begin{array}{l}2.29 \\
1.463 \\
3.76 \\
6.45\end{array}$ & $\begin{array}{c}1.05-5.00 \\
0.48-4.44 \\
0.57-24.84 \\
1.81-22.94\end{array}$ \\
\hline $\begin{array}{l}\text { III. CNS neoplasms } \\
\text { Low grade } \\
\text { High grade } \\
\text { Unspecified }\end{array}$ & $\begin{array}{l}7(132) \\
6(91) \\
0(15) \\
1(26)\end{array}$ & $\begin{array}{c}2.41 \\
2.94 \\
\star \\
1.84\end{array}$ & $\begin{array}{c}1.17-4.95 \\
1.36-6.38 \\
* \\
0.27-12.541\end{array}$ \\
\hline VIII. Malignant bone tumours & $4(37)$ & 4.77 & $1.89-12.06$ \\
\hline IX. Soft tissue sarcomas & $1(34)$ & 1.32 & $0.19-9.14$ \\
\hline X. Germ cell and other gonadal neoplasms & $38(349)$ & 3.70 & $2.69-5.09$ \\
\hline \multicolumn{4}{|c|}{ XI. Carcinomas and other malignant epithelial neoplasms } \\
\hline $\begin{array}{l}\text { Thyroid carcinoma } \\
\text { Malignant melanoma }\end{array}$ & $\begin{array}{l}2(20) \\
1(80)\end{array}$ & $\begin{array}{l}4.36 \\
0.45\end{array}$ & $\begin{array}{l}1.17-16.31 \\
0.06-3.21\end{array}$ \\
\hline \multicolumn{4}{|c|}{ 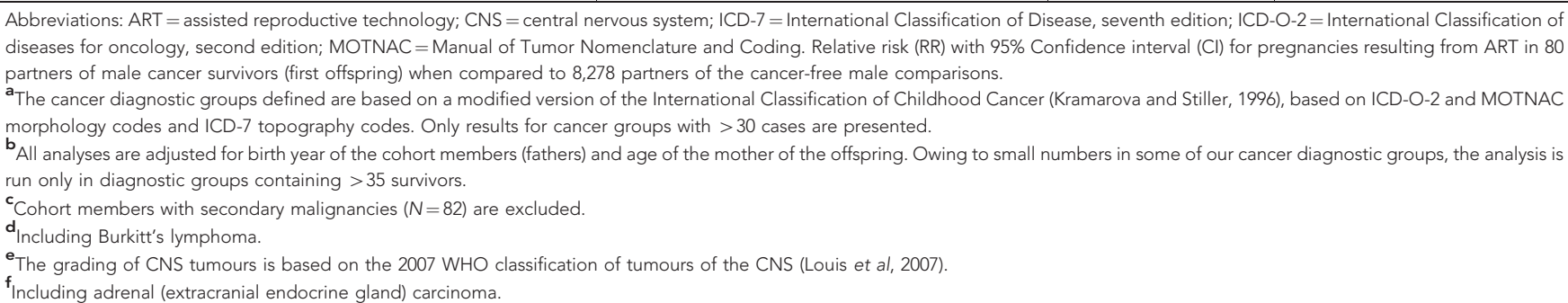 } \\
\hline
\end{tabular}

ART among the male cancer survivors in our study, we could not demonstrate an increased risk of negative outcomes among their offspring. This applied also when studying the offspring of ART only, in a separate analysis, although the numbers were too small to firmly conclude (Supplementary Table). Several published studies have explored the relationship between a cancer diagnosis and the probability of having children (Madanat et al, 2008; Magelssen et al, 2008; Green et al, 2010; Hudson, 2010). Most, although not all, show reduced reproduction after surviving a cancer diagnosis, in childhood, adolescence and in young adult age (Syse et al, 2007), also depending on the site and stage of the cancer. There is, to our knowledge, no population-based study to date looking at the interplay of paternity, assisted reproduction, marriage and offspring outcomes in a national cohort of male survivors of cancer diagnosed in childhood, adolescence and young adulthood. The current study therefore adds important information regarding these complex and interconnected issues, by studying them in a population perspective.

We did not have complete information in our registries on cohabitation rates and therefore used marriage as a marker for the ability to sustain long-term relationships and establishing a family unit. There is no evidence to support that childless cancer survivors would marry more or less frequently (compared with cohabitating without marrying) than the childless non-cancer males (Syse, 2008), nor did we find that the age at first marriage differed (data not shown). In order to take into account socioeconomic status as a possible factor influencing marriage and paternity, we adjusted all analyses for educational achievement (highest education achieved) of the parents of the cohort (as many of the cohort members might not have completed their education at the time of analysis), which did not change our estimates.

Studies have looked at cohabitation/marriage rates in cancer survivors compared with siblings or with the cancer-free general population, with somewhat conflicting results (Frobisher et al, 2007; Gurney et al, 2009; Koch et al, 2011; Kirchhoff et al, 2012; Wengenroth et al, 2013). Syse (2008) did not find reduced marriage rates in male survivors of any types of cancer (before age 44 years) in Norway, compared with the male population as a whole, and only a nonsignificant slightly lower probability for brain tumour survivors to marry, as well as an increased marriage rate for survivors of testicular cancer. This is, despite a partial overlap in study populations, contrary to our findings and probably reflects the crucial timing of the treatment insult for young male brain cancer patients in our study, as well as the fact that childhood cancer survivors only contribute marginally to the overall estimates for male survivors in the publication by Syse. A Danish registry-based study (Koch et al, 2011) found a reduced rate of cohabitation for childhood cancer survivors in general and the largest deficit was found for survivors of CNS tumours, which correspond well with our results.

We did not find an increased risk for detrimental effects of a history of cancer in male survivors on pre- and perinatal outcomes of their firstborn offspring. This has also been demonstrated in two previous Norwegian studies (Magelssen et al, 2008; Stensheim et al, 2013), 
which have partly overlapping data with ours, although only studying cancer diagnosed at 15 and 16 years and above, respectively. However, there have been conflicting results published with regards to the risk of congenital malformations in the offspring of male cancer patients (Magelssen et al, 2008; Winther et al, 2009; Ståhl et al, 2011; Signorello et al, 2012; Stensheim et al, 2013). A Norwegian (Magelssen et al, 2008) and a Swedish (Ståhl et al, 2011) study found an increased risk of congenital abnormalities in the offspring of male cancer survivors. However, in the Norwegian study the data were from one hospital only, cancers were diagnosed at age 15-35 years and the numbers studied were relatively small. In the latter study, cancer was diagnosed at all ages and there was no treatment data available. The publications that were able to explore directly the link between treatment exposure (especially radiation therapy to the gonads and alkylating chemotherapy) and genetic disease in the offspring (Signorello et al, 2012; Winther et al, 2012) could not provide evidence for a causal relationship, which is in concordance with our results (although we were not able to study treatment exposures directly).

We briefly studied the impact of the diagnostic time period and age at cancer diagnosis. As there are various co-dependent time factors associated with a prospective study of a cancer cohort such as ours, this could not be thoroughly studied within our design. Some studies on adult survivors of cancer in young age have described a reduction in late effects in survivors being treated with more modern, and presumably less intense, treatment regimens (Cvancarova et al, 2009; Stensheim et al, 2011), which is in concordance with our results. Conflicting evidence exist with regard to whether the prepubertal testis is protected from cytotoxic insults or not (Rivkees, 1988; Green et al, 2014), although the most recent publication cannot find any protective effect of being treated pre-pubertally with alkylating agent chemotherapy on subsequent adult sperm concentration. Our results suggest vulnerability in children younger than 15 years at diagnosis. This may be attributable to the fact that childhood cancers more often require intensive, multi-modal therapy when compared with young adult cancer, more so than a biological inherent vulnerability to the toxicity of cancer treatment in pre-pubertal children. As we have no access to treatment exposures in our study, we are not able to explore this in detail. Owing to the selection of our cohort, the male cancer survivors in the oldest age group at diagnosis will have been treated with more modern treatment regimens and also at a time when fertility preservation was becoming more available in Norway (Stensvold et al, 2011).

As we use the national registry data, our data overlap in part with earlier Norwegian studies published (Syse et al, 2007; Magelssen et al, 2008; Syse, 2008; Stensheim et al, 2011, 2013). Our findings, when comparable, line up well with existing, overall conclusions and do not provide evidence that male childhood cancer survivors (not included in all previous publications) in general fare worse than survivors diagnosed with cancer at an older age. This is an important information for the growing population of childhood cancer survivors. Unfortunately, it is not possible to disentangle the possible influences of data overlap versus nonoverlap and actual changes that have taken place in more recent times, based on the published information. By jointly considering birth outcomes, parenthood and marriage in a recent time period in a complete national cohort, we contribute novel, updated information on important aspects of adult living for Norwegian male survivors of cancer diagnosed before 25 years of age. This might be transferable to male cancer survivors not only in the Nordic countries but also in non-Nordic countries, which share some of the Nordic welfare traits, and hopefully will contribute to developing adequate counselling and follow-up strategies for male survivors of cancer in young age, during their transition into and passage through adulthood.
Although a large proportion of male survivors of cancer in young age will be able to establish a family and father children, there is still room for improvement, especially with regards to decreasing the toxicity burden of current treatment regimens, as well as improving fertility preservation methods and access to these for young male cancer patients.

\section{ACKNOWLEDGEMENTS}

This study was supported by the Western Norway Regional Health Authority (grant number 911612) and the Norwegian Cancer Society. We thank Øystein Haaland for assistance creating Figure 1.

\section{CONFLICT OF INTEREST}

The authors declare no conflict of interest.

\section{REFERENCES}

American Cancer Society (1968) Task force to revise the manual of tumor nomenclature and coding for the American Cancer Society. Manual of Tumor Nomenclature and Coding. American Cancer Society: New York.

Cancer registry of Norway (2013) Available at http://www.kreftregisteret.no.

Cvancarova M, Samuelsen SO, Magelssen H, Fosså SD (2009) Reproduction rates after cancer treatment: experience from the Norwegian radium hospital. J Clin Oncol 27: 334-343.

de Fine Licht S, Winther JF, Gudmundsdottir T, Holmqvist AS, Bonnesen TG, Asdahl PH, Tryggvadottir L, Anderson H, Wesenberg F, Malila N, Holm K, Hasle H, Olsen JH (2014) Hospital contacts for endocrine disorders in Adult Life after Childhood Cancer in Scandinavia (ALiCCS): a population-based cohort study. Lancet 6736: 1-9.

Dörffel W, Rühl U, Lüders H, Claviez A, Albrecht M, Bökkerink J, Holte H, Karlen J, Mann G, Marciniak H, Niggli F, Schmiegelow K, Schwarze EW, Pötter R, Wickmann L, Schellong G (2013) Treatment of children and adolescents with hodgkin lymphoma without radiotherapy for patients in complete remission after chemotherapy: final results of the multinational trial GPOH-HD95. J Clin Oncol 31: 1562-1568.

EUROCAT (2012) European Surveillance of Congenital Anomalies. Available at http://www.eurocat-network.eu/aboutus/datacollection/ guidelinesforregistration/malformationcodingguides.

Fosså SD, Kravdal O (2000) Fertility in Norwegian testicular cancer patients. Br J Cancer 82: 737-741.

Frobisher C, Lancashire ER, Winter DL, Jenkinson HC, Hawkins MM (2007) Long-term population-based marriage rates among adult survivors of childhood cancer in Britain. Int J Cancer 121: 846-855.

García A, Herrero MB, Holzer H, Tulandi T, Chan P (2014) Assisted reproductive outcomes of male cancer survivors. J Cancer Surviv 9 208-214.

Gatta G, Botta L, Rossi S, Aareleid T, Bielska-Lasota M, Clavel J, Dimitrova N, Jakab Z, Kaatsch P, Lacour B, Mallone S, Marcos-Gragera R, Minicozzi P, Sánchez-Pérez M-J, Sant M, Santaquilani M, Stiller C, Tavilla A, Trama A, Visser O, Peris-Bonet R (2014) Childhood cancer survival in Europe 1999-2007: results of EUROCARE-5-a population-based study. Lancet Oncol 15: 35-47.

Geenen MM, Cardous-Ubbink MC, Kremer LCM, Heinen RC, Jaspers MWM, Koning CCE, Hart AAM, Bakker PJM (2007) Clinicians corner: medical assessment of adverse health outcomes in long-term survivors of childhood cancer. J Am Med Assoc 297: 2705-2715.

GPOH (2015) Gesellschaft für Pädiatrische Onkologie und Hämatologie. EuroNet-PHL-C1. Available at http://www.kinderkrebsinfo.de/health professionals/clinical_trials/pohkinderkrebsinfotherapiestudien/euronet_ phl_cl/index_eng.html.

Green DM, Kawashima T, Stovall M, Leisenring W, Sklar CA, Mertens AC, Donaldson SS, Byrne J, Robison LL (2010) Fertility of male survivors of childhood cancer: a report from the Childhood Cancer Survivor Study. J Clin Oncol 28: 332-339. 
Green DM, Kawashima T, Stovall M, Leisenring W, Sklar CA, Mertens AC, Donaldson SS, Byrne J, Robison LL (2009) Fertility of female survivors of childhood cancer: a report from the Childhood Cancer Survivor Study. J Clin Oncol 27: 2677-2685.

Green DM, Liu W, Kutteh WH, Ke RW, Shelton KC, Sklar CA, Chemaitilly W, Pui C-H, Klosky JL, Spunt SL, Metzger ML, Srivastava D, Ness KK, Robison LL, Hudson MM (2014) Cumulative alkylating agent exposure and semen parameters in adult survivors of childhood cancer: a report from the St Jude Lifetime Cohort Study. Lancet Oncol 15: 1215-1223.

Gudmundsdottir T, Winther JF, de Fine Licht S, Bonnesen TG, Asdahl PH, Tryggvadottir L, Anderson H, Wesenberg F, Malila N, Hasle H, Olsen JH (2015) Cardiovascular disease in adult life after childhood cancer in Scandinavia: a population-based cohort study of 3-2,308 one-year survivors. Int J Cancer 137: 1176-1186.

Gurney JG, Krull KR, Kadan-Lottick N, Nicholson HS, Nathan PC, Zebrack B, Tersak JM, Ness KK (2009) Social outcomes in the Childhood Cancer Survivor Study Cohort. J Clin Oncol 27: 2390-2395.

Gustafsson G, Kreuger A, Clausen N, Garwics S, Kristinsson J, Lie SO, Moe PJ, Perkkio M, Yssing M, Saarinen-Pihkala UM (1998) Intensified treatment of acute childhood lymphoblastic leukaemia has improved prognosis, especially in non-high-risk patients: the Nordic experience of 2648 patients diagnosed between 1981 and 1996. Nordic Society of Paediatric Haematology and Oncology (NOPHO). Acta Paediatr 87: 1151-1161.

Gustafsson G, Schmiegelow K, Forestier E, Clausen N, Glomstein A, Jonmundsson G, Mellander L, Mäkipernaa A, Nygaard R, Saarinen-Pihkala UM (2000) Improving outcome through two decades in childhood ALL in the Nordic countries: the impact of high-dose methotrexate in the reduction of CNS irradiation. Leukemia 14: 2267-2275.

Hudson MM (2010) Reproductive outcomes for survivors of childhood cancer. Obstet Gynecol 116: 1171-1183.

Hudson MM, Ness KK, Gurney JG, Mulrooney DA, Krull KR, Green DM, Armstrong GT, Nottage KA, Jones KE, Sklar CA (2013) Clinician's corner clinical ascertainment of health outcomes among adults treated for childhood cancer. J Am Med Assoc 309: 2371-2381.

Irgens LM (2000) The Medical Birth Registry of Norway. Epidemiological research and surveillance throughout 30 years. Acta Obstet Gynecol Scand 79: 435-439.

Jairam V, Robert KB, Yu JB (2013) Historical trends in the use of radiation therapy for pediatric cancers: 1973-2008. Int J Radiat Oncol Biol Phys 85: e151-e155.

Kirchhoff AC, Yi J, Wright J, Warner EL, Smith KR (2012) Marriage and divorce among young adult cancer survivors. J Cancer Surviv 6: 441-450.

Kiserud CE, Fosså A, Holte H, Fosså SD (2007) Post-treatment parenthood in Hodgkin's lymphoma survivors. Br J Cancer 96: 1442-1449.

Koch SV, Kejs AMT, Engholm G, Møller H, Johansen C, Scmiegelow K (2011) Marriage and divorce among childhood cancer survivors. J Pediatr Hematol Oncol 33(7): 500-505.

Kramarova E, Stiller CA (1996) The International Classification of Childhood Cancer. Int J Cancer 68: 759-765.

Larsen IK, Småstuen M, Johannesen TB, Langmark F, Parkin DM, Bray F, Møller B (2009) Data quality at the Cancer Registry of Norway: an overview of comparability, completeness, validity and timeliness. Eur J Cancer 45: 1218-1231.

Louis DN, Ohgaki H, Wiestler OD, Cavenee WK, Burger PC, Jouvet A, Scheithauer BW, Kleihues P (2007) The 2007 WHO Classification of tumours of the central nervous system. Acta Neuropathol 114: 97-109.

Madanat L-MS, Malila N, Dyba T, Hakulinen T, Sankila R, Boice JD, Lähteenmäki PM (2008) Probability of parenthood after early onset cancer: a population-based study. Int J Cancer 123: 2891-2898.

Magelssen H, Melve KK, Skjaerven R, Fosså SD (2008) Parenthood probability and pregnancy outcome in patients with a cancer diagnosis during adolescence and young adulthood. Hum Reprod 23: 178-186.

Medical Birth Registry of Norway (2013) Norwegian Institute of Public Health. Available at http://www.fhi.no/eway/default.aspx?pid=240\&trg=List_ 6673\&Main_6664=7003:0:25,7366\&List_6673=6674:0:25,7840:1:0:0::00:0.

Moe PJ, Holen A, Glomstein A, Madsen B, Hellebostad M, Stokland T, Wefring KW, Steen-Johnsen J, Nielsen B, Howlid H, Børsting S, Hapnes C (1997) Long-term survival and quality of life in patients treated with a national all protocol 15-20 years earlier: IDM/HDM and late effects? Pediatr Hematol Oncol 14: 513-524.

Moe PJ, Seip M, Finne PH (1981) Intermediate dose methotrexate (IDM) in childhood acute lymphocytic leukemia in Norway. Preliminary results of a national treatment program. Acta Paediatr Scand 70: 73-79.
Molven O, Ferkis J (2011) Healthcare, Welfare and Law Health Legislation as a Mirror of the Norwegian Welfare State. Gyldendal: Oslo.

National Education Database (2013) About the National Education Database (NUDB). Available at http://www.ssb.no/a/english/mikrodata/ datasamling/nudb/nudb_20130607-en.html.

Norwegian Tax Administration (2015) Tax in Norway. Available at https://www.skatteetaten.no/en/International-pages/Felles-innholdbenyttes-i-flere-malgrupper/Articles/Tax-in-Norway/.

Oeffinger KC, Mertens AC, Sklar CA, Kawashima T, Hudson MM, Meadows AT, Friedman DL, Marina N, Hobbie W, Kadan-Lottick NS, Schwartz CL, Leisenring W, Robison LL (2006) Chronic health conditions in adult survivors of childhood cancer. N Engl J Med 355: 1572-1582.

Olsen JH, Möller T, Anderson H, Langmark F, Sankila R, Tryggvadóttir L, Winther JF, Rechnitzer C, Jonmundsson G, Christensen J, Garwics S (2009) Lifelong cancer incidence in 47697 patients treated for childhood cancer in the nordic countries. J Natl Cancer Inst 101(11): 806-816.

Pritchard-Jones K, Pieters R, Reaman GH, Hjorth L, Downie P, Calaminus G, Naafs-Wilstra MC, Steliarova-Foucher E (2013) Sustaining innovation and improvement in the treatment of childhood cancer: lessons from high-income countries. Lancet Oncol 14: e95-e103.

Reulen RC, Zeegers MP, Wallace WHB, Frobisher C, Taylor AJ, Lancashire ER, Winter DL, Hawkins MM (2009) Pregnancy outcomes among adult survivors of childhood cancer in the British Childhood Cancer Survivor Study. Cancer Epidemiol Biomarkers Prev 18: 2239-2247.

Rivkees SA (1988) The relationship of gonadal activity and chemotherapyinduced gonadal damage. J Am Med Assoc 259: 2123.

Romundstad LB, Romundstad PR, Sunde A, von Düring V, Skjaerven R, Gunnell D, Vatten LJ (2008) Effects of technology or maternal factors on perinatal outcome after assisted fertilisation: a population-based cohort study. Lancet 372: 737-743.

Signorello LB, Mulvihill JJ, Green DM, Munro HM, Stovall M, Weathers RE, Mertens AC, Whitton JA, Robison LL, Boice JD (2012) Congenital anomalies in the children of cancer survivors: a report from the Childhood Cancer Survivor Study. J Clin Oncol 30: 239-245.

Skjærven R, Gjessing HK, Bakketeig L (2000) Birthweight by gestational age in Norway. Acta Obstet Gynecol Scand 79: 440-449.

Steliarova-Foucher E, Stiller C, Kaatsch P, Berrino F, Coebergh J, Lacour B, Parkin M (2004) Geographical patterns and time trends of cancer incidence and survival among children and adolescents in Europe since the 1970s (the ACCIS project): an epidemiological study. Lancet 364: 2097-2105.

Stensheim H, Cvancarova M, Møller B, Fosså SD (2011) Pregnancy after adolescent and adult cancer: a population-based matched cohort study. Int J Cancer 129: 1225-1236.

Stensheim H, Klungsøyr K, Skjaerven R, Grotmol T, Fosså SD (2013) Birth outcomes among offspring of adult cancer survivors: a populationbased study. Int J Cancer 133: 2696-2705.

Stensvold E, Magelssen H, Oskam IC (2011) Fertility-preserving measures for boys and young men with cancer. Tidsskr Nor Laegeforening 131: 1433-1435.

Ståhl O, Boyd HA, Giwercman A, Lindholm M, Jensen A, Kjær SK, Anderson H, Cavallin-Ståhl E, Rylander L (2011) Risk of birth abnormalities in the offspring of men with a history of cancer: a cohort study using Danish and Swedish national registries. J Natl Cancer Inst 103: 398-406.

Syse A (2008) Does cancer affect marriage rates? J Cancer Surviv 2: 205-214.

Syse A, Kravdal Ø, Tretli S (2007) Parenthood after cancer: A populationbased study. Psychooncology 16: 920-927.

Tromp K, Claessens JJM, Knijnenburg SL, van der Pal HJH, van Leeuwen FE, Caron HN, Beerendonk CCM, Kremer LCM (2011) Reproductive status in adult male long-term survivors of childhood cancer. Hum Reprod 26: $1775-1783$.

Van Dorp W, Van Der Geest IMM, Laven JS, Hop WC, Neggers SJ, de Vries AC, Pieters R, van Den Heuvel-Eibrink MM (2012) Gonadal function recovery in very long-term male survivors of childhood cancer. Eur J Cancer 49: 1280-1286.

Ward E, DeSantis C, Robbins A, Kohler B, Jemal A (2014) Childhood and adolescent cancer statistics. CA Cancer J Clin 64: 83-103.

Wasilewski-Masker K, Seidel KD, Leisenring W, Mertens AC, Shnorhavorian M, Ritenour CW, Stovall M, Green DM, Sklar CA, Armstrong GT, Robison LL, Meacham LR (2014) Male infertility in long-term survivors of pediatric cancer: a report from the childhood cancer survivor study. J Cancer Surviv 8: $437-447$. 
Wengenroth L, Rueegg CS, Michel G, Essig S, Ammann RA, Bergstraesser E, Kuehni CE. Paediatric S, Group O (2013) Life partnerships in childhood cancer survivors, their siblings, and the general population. Pediatr Blood Cancer 61: 538-545.

Winther JF, Boice Jr JD, Frederiksen K, Bautz A, Mulvihill JJ, Stovall M, Olsen JH (2009) Radiotherapy for childhood cancer and risk for congenital malformations in offspring: a population-based cohort study. Clin Genet 75: 50-56.

Winther JF, Olsen JH, Wu H, Shyr Y, Mulvihill JJ, Stovall M, Nielsen A, Schmiegelow M, Boice JD Jr (2012) Genetic disease in the children of danish survivors of childhood and adolescent cancer. J Clin Oncol 30: $27-33$.
World Health Organization (1957) Manual of the International Statistical Classification of Diseases, Injuries and Causes of Death, Seventh Revision. Available at https://extranet.who.int/iris/restricted/handle/10665/42900.

World Health Organization (1990) International Classification of Diseases for Oncology, Second Edition. Available at https:/extranet.who.int/iris/ restricted/handle/10665/39441.

(c) (i) (2) (2) This work is licensed under the Creative Commons com Ac SA Atribution-Non-Commercial-Share Alike 4.0 International License. To view a copy of this license, visit http:// creativecommons.org/licenses/by-nc-sa/4.0/

Supplementary Information accompanies this paper on British Journal of Cancer website (http://www.nature.com/bjc) 